\title{
Amorpha-4,11-diene synthase: a key enzyme in artemisinin biosynthesis and engineering
}

\author{
Jin Quan Huang ${ }^{1}$, Xin Fang ${ }^{2 \varpi_{(}}$ \\ ${ }^{1}$ National Key Laboratory of Plant Molecular Genetics, Institute of Plant Physiology and Ecology/CAS Center for \\ Excellence in Molecular Plant Sciences, Chinese Academy of Sciences, Shanghai 200032, People's Republic of China \\ 2 State Key Laboratory of Phytochemistry and Plant Resources in West China, Kunming Institute of Botany, Chinese \\ Academy of Sciences, Kunming 650204, Yunnan, People's Republic of China
}

Received: 8 February 2021 / Accepted: 16 July 2021 / Published online: 30 July 2021

\begin{abstract}
Amorpha-4,11-diene synthase (ADS) catalyzes the first committed step in the artemisinin biosynthetic pathway, which is the first catalytic reaction enzymatically and genetically characterized in artemisinin biosynthesis. The advent of ADS in Artemisia annua is considered crucial for the emergence of the specialized artemisinin biosynthetic pathway in the species. Microbial production of amorpha-4,11diene is a breakthrough in metabolic engineering and synthetic biology. Recently, numerous new techniques have been used in ADS engineering; for example, assessing the substrate promiscuity of ADS to chemoenzymatically produce artemisinin. In this review, we discuss the discovery and catalytic mechanism of ADS, its application in metabolic engineering and synthetic biology, as well as the role of sesquiterpene synthases in the evolutionary origin of artemisinin.
\end{abstract}

Keywords Amorpha-4,11-diene Synthase, Artemisinin, Catalytic mechanism, Metabolic engineering, Synthetic biology

\section{INTRODUCTION}

Artemisinin is a well-known antimalarial drug against chloroquine-resistant strains of Plasmodium falciparum (Chen and Xu 2016; Wang et al. 2019). In 2002, the World Health Organization recommended artemisininbased combinatorial therapies as the first-line treatment for uncomplicated malaria. Artemisia annua $\mathrm{L}$. is the only natural source of artemisinin, which is biosynthesized and accumulated in the glandular trichome cells of the plant. A recent study has proved that artemisinin is also produced in the non-glandular trichome cells (Judd et al. 2019). The low content of artemisinin in A. annua (0.1-1.0\% of dry weight) makes its plant-derived production insufficient for global requirements (Ikram and Simonsen 2017). Recent advances in metabolic

$\bowtie$ Correspondence: xinfang@mail.kib.ac.cn (X. Fang) engineering and synthetic biology have enabled higher yield of artemisinin in microbial or plant heterologous hosts by engineering the artemisinin pathway genes in these hosts. However, complete understanding of artemisinin biosynthesis is still required (Fig. 1).

The first step toward the elucidation of the artemisinin biosynthetic pathway began in 1999, when amorpha-4,11-diene synthase (ADS) was purified from A. annua and functionally characterized (Bouwmeester et al. 1999). Since then, studies have been extensively conducted to understand the artemisinin biosynthetic pathway and its evolutionary origin and to develop metabolic engineering and biosynthetic methods for its production. Notably, stable and high-yielding production of artemisinic acid was established in Saccharomyces cerevisiae and chemical conversion of artemisinic acid effectively yielded artemisinin (Paddon and Keasling 2014). Recently, the production of amorpha-4,11-diene 
A

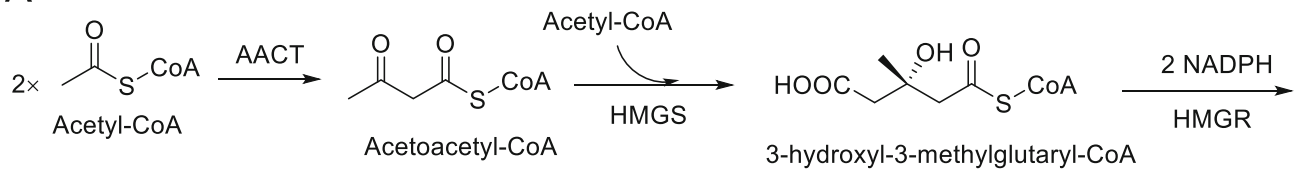

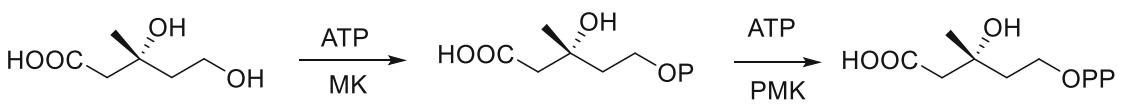

3R-Mevalonic acid (MVA) Mevalonic acid-5-phosphate Mevalonate diphosphate

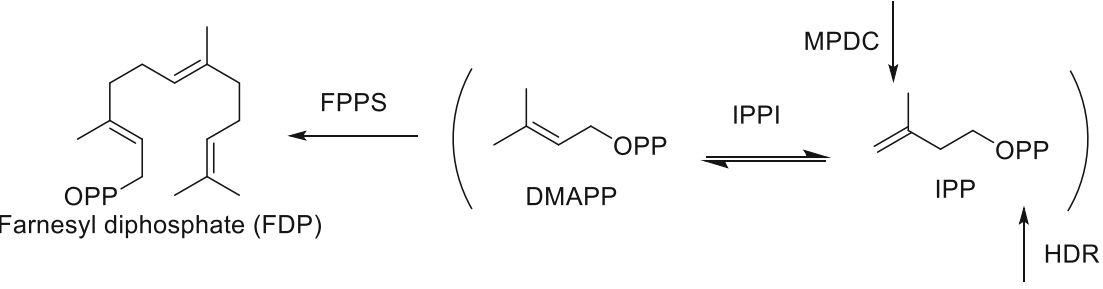

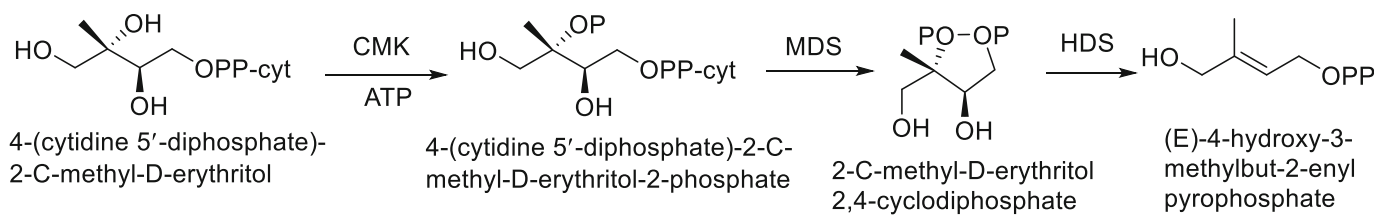

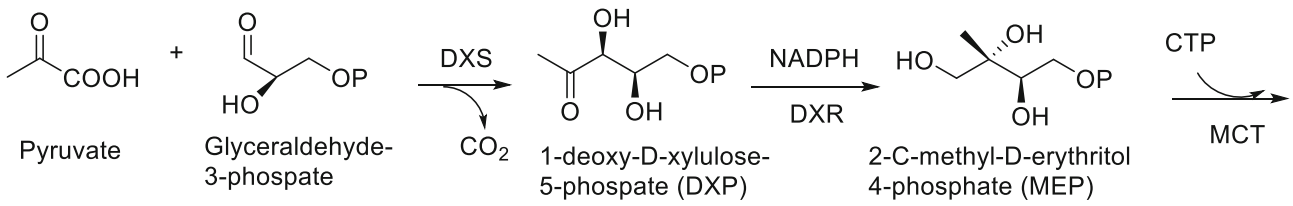

B

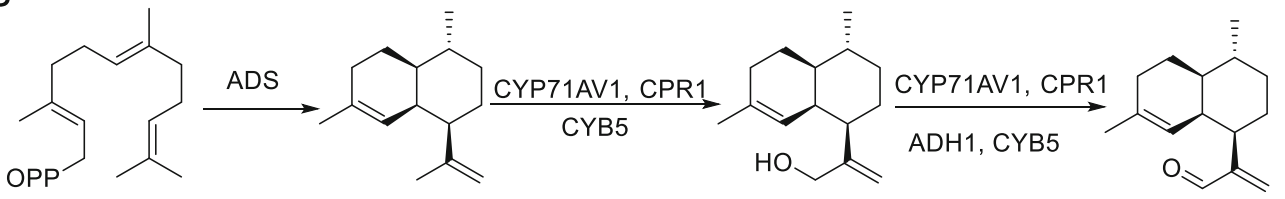

FDP

amorpha-4,11-diene

artemisinic alcohol

artemisinic aldehyde

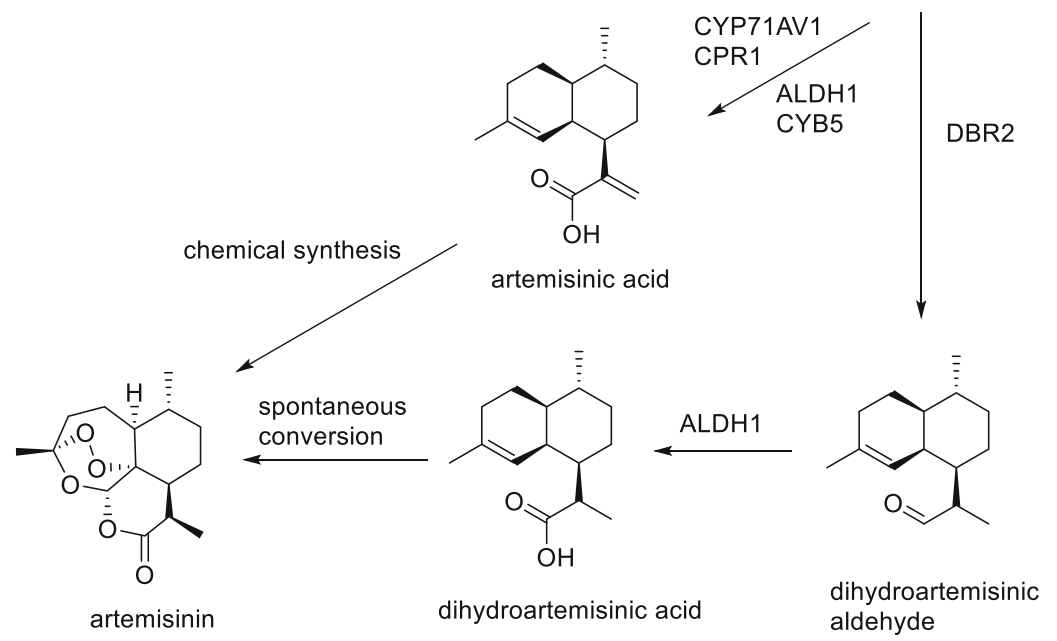


4Fig. 1 Proposed artemisinin biosynthetic pathway in A. annua. A. Carbon flow from MVA (in the cytosol) and MEP (in the chloroplast) pathways to form FDP. AACT, acetyl-coenzyme transferase; HMGS and HMGR, 3-hydroxy-3-methylglutaryl-CoA synthase and reductase; MK, 3R-mevalonic acid kinase; PMK, mevalonic acid-5-phosphate kinase; MPDC, mevalonate 5-pyrophosphate decarboxylase; DXS and DXR, 1-deoxy-D-xylulose 5-phosphate synthase and reductase; MCT, 2-C-methyl-D-erythritol 2,4-cyclodiphosphate synthase; CMK, 4-diphosphocytidyl-2-Cmethyl-D-erythritol kinase; MDS, 2-C-methyl-D-erythritol 2,4cyclodiphosphate synthase; HDS and HDR, 4-hydroxy-3-methylbut-2-enyl pyrophosphate synthase and reductase; IPPI, isopentenyl pyrophosphate isomerase; FPPS, farnesyl pyrophosphate synthase. B. Production of artemisinin in planta and by biological methods. ADS, armorpha-4,11-diene synthase; CYP71AV1, cytochrome P450 monooxygenase; CPR1, cytochrome $\mathrm{P} 450$ reductase 1; CYB5, cytochrome b5 monooxygenase; ALDH1, aldehyde dehydrogenase; DBR2, artemisinic aldehyde delta-11(13)-double bond reductase. Enzymes marked in red improved the efficiency of different oxidation steps in yeast (Paddon et al. 2013)

has become a touchstone technique because of its important role in metabolic engineering and synthetic biology (Choi et al. 2016; Orsi et al. 2020; ReddingJohanson et al. 2011; Shukal et al. 2019; Wang et al. 2013; Yuan and Ching 2014, 2015a, 2015b, 2016). Furthermore, the substrate promiscuity of ADS was used to develop a chemoenzymatic strategy for artemisinin production (Demiray et al. 2017). The importance of ADS still attracts considerable research attention.

Because advances in the investigation of artemisinin biosynthesis as well as in metabolic engineering or synthetic biology for artemisinin production have been previously reviewed (Farhi et al. 2013; Ikram and Simonsen 2017; Kung et al. 2018; Xie et al. 2016), herein, we mainly focus on the discovery, catalytic mechanism, and engineering of ADS, as well as the impact of the emergence of $A D S$ in the evolutionary origin of artemisinin biosynthetic pathway in this review.

\section{CHARACTERIZATION, CATALYTIC MECHANISM, AND EVOLUTIONARY ORIGIN OF ADS}

Structurally, artemisinin is an endoperoxide sesquiterpene lactone in which the basic carbon skeleton is constructed from farnesyl diphosphate (FDP) by a sesquiterpene synthase. In 1999, a native ADS protein was purified from A. annua and functionally characterized, suggesting that ADS may catalyze the first ratedetermining step in artemisinin biosynthesis (Bouwmeester et al. 1999). Several groups have isolated terpene synthase genes from $A$. annua and bacterially expressed them in Escherichia coli, resulting in the identification of ADS (Chang et al. 2000; Mercke et al. 2000; Wallaart et al. 2001) and other terpene synthases, such as (3R)-linalool synthase (Jia et al. 1999), 8-epicedrol synthase (Hua and Matsuda 1999; Mercke et al. 1999), and $\beta$-caryophyllene synthase (Cai et al. 2002), from A. annua. Overexpression and downregulation of $A D S$ in $A$. annua plants resulted in increased and reduced artemisinin content in planta, respectively, providing direct genetic evidence of the involvement of ADS in artemisinin biosynthesis (Alam and Abdin 2011; Catania et al. 2018; Han et al. 2016; Ma et al. $2009,2015)$. These studies have paved the way for further investigation of artemisinin biosynthesis.

ADS is a class I terpenoid synthase (TPS) belonging to the plant TPS-a subgroup (Salmon et al. 2015). It contains conserved DDXXD (DDTYD) and NSE/DTE (NDLMTHKAE) ion-binding motifs (Chang et al. 2000; Mercke et al. 2000). Accordingly, the effects of divalent metal ions, such as $\mathrm{Mg}^{2+}, \mathrm{Mn}^{2+}, \mathrm{Co}^{2+}, \mathrm{Ni}^{2+}, \mathrm{Zn}^{2+}$, and $\mathrm{Cu}^{2+}$, on enzyme activity were tested. No activity was reported when $\mathrm{Ni}^{2+}, \mathrm{Zn}^{2+}$, and $\mathrm{Cu}^{2+}$ were used, and the enzyme activity was lower with $\mathrm{Mn}^{2+}$ and $\mathrm{Co}^{2+}$ than with $\mathrm{Mg}^{2+}$ (Picaud et al. 2005). ADS showed $36 \%$ and $41 \%$ amino acid sequence identity with tobacco 5-epiaristolochene synthase (TEAS) and cotton $(+)-\delta$-cadinene synthase, respectively (Chang et al. 2000). Similar to the crystal structure of TEAS, ADS also has an $\mathrm{N}$-terminal glycosyl hydrolase domain and a C-terminal catalytic domain (Mercke et al. 2000).

The catalytic mechanism of ADS has attracted continued interest. Generally, the catalytic mechanism of a class I TPS involves the initial ionization of the substrate diphosphate group, electrophilic cyclization, deprotonation, or capture of a nucleophile, and finally, the release of neutral products (Christianson 2017). Methods used to investigate mechanistic details involve labeled substrates and mutant enzymes and include X-ray crystallography and quantum chemical study (Faraldos et al. 2012). A catalytic model of ADS was suggested by the observation of TEAS, in which FDP binding placed Phe ${ }^{525}$ next to $\operatorname{Trp}^{271}$ to form an extended aromatic box, and the carbocation intermediates were stabilized by the nucleophilicity of the $\operatorname{Trp}^{271}$ indole ring. The ionization of FDP was facilitated by the positive charges of $\operatorname{Arg}^{262}$ and $\mathrm{Arg}^{440}$ with the help of divalent metal cations coordinated by the DDXXD motif. Other motifs including the $\mathrm{Arg}^{10}-\mathrm{Pro}^{11}$ pair and the $\mathrm{Asp}^{444}-\mathrm{Tyr}^{520}-\mathrm{Asp}^{524}$ triad were also conserved in ADS, but their function was not experimentally investigated (Chang et al. 2000; Mercke et al. 2000).

The bicyclic structure of amorpha-4,11-diene is formed by an initial 1,6 or 1,10 cyclization of FDP 
involving a bisabolyl or (2Z,6E)-germacradienyl cation, respectively (Chang et al. 2000). The recombinant ADS expressed in $E$. coli produces the by-products $\beta$ sesquiphellandrene, $\alpha$-bisabolol, zingiberene, and zingibernol, supporting the involvement of a bisabolyl cation in the cyclization mechanism (Mercke et al. 2000; Picaud et al. 2005). By using deuterium-labeled FDP (labeled at C-1) as a chemical probe, two study groups independently found that $\mathrm{H}-1$ migrated to the original C-7 of FDP (C-10 of amorpha-4,11-diene). They deduced the occurrence of the initial 1,6 cyclization because the initial 1,10-ring closure led to the shift of $\mathrm{H}-1$ to $\mathrm{C}-11$ (Kim et al. 2006; Picaud et al. 2006). However, a subsequent 1,5-hydride shift could also allow the migrating $\mathrm{H}-1$ to relocate to the original C-7 of FDP (Fig. 2), indicating that these two cyclization mechanisms cannot be determined by using labeled substrates. Indeed, a quantum chemical study concluded that the 1,5-hydride shift is feasible, supporting the occurrence of the initial 1,10 cyclization for the catalytic mechanism of ADS (Hong and Tantillo 2010). Recently, the ADS Q518L variant was reported to generate the initial 1,10 cyclization product $\beta$-copaene in addition to amorpha4,11-diene (Fig. 2), implying that ADS uses both initial 1,6 and 1,10 cyclization mechanisms to produce amorpha-4,11-diene (Huang et al. 2021).

New terpenoid biosynthetic pathways usually initiate from the emergence of functional TPS/CYP gene pairs (Boutanaev et al. 2015), but the sequence of their occurrence is not fixed. Regarding the evolutionary emergence of the artemisinin biosynthetic pathway in $A$. annua, Nguyen et al. (2010) suggested that the occurrence of $A D S$ is a dominant event mainly shaped by an Y374L mutation in its progenitor (Salmon et al. 2015). They found that in all major subfamilies of Asteraceae, germacrene A oxidase (GAO) is conserved when producing germacrene A acid, the key intermediate of the Asteraceae sesquiterpene lactone biosynthetic pathway (Fig. 3). Remarkably, GAO uses amorpha-4,11-diene as the substrate to produce artemisinic acid, whereas CYP71AV1 or amorpha-4,11-diene oxidase (AMO) is inactive to germacrene A. Thus, they hypothesized that the advent of ADS activity in A. annua removed GAO from the Asteraceae sesquiterpene lactone biosynthetic pathway and eventually replaced it with AMO. In addition, sesquiterpene lactones derived from germacrene $\mathrm{A}$ are absent in A. annua but are present in other Artemisia species (Bertea et al. 2006). The promiscuity of GAO and the specificity of AMO were further confirmed by the ability of GAO to oxidize several sesquiterpenes, including germacrene D, 5-epi-aristolochene, valencene, $\delta$-cadinene, $\alpha$ - and $\delta$-guaienes, and valerenadiene to corresponding sesquiterpene acids, whereas AMO showed negligible activities (Nguyen et al. 2019). Similarly, orthologs of CYP71AV1 ( $94 \%$ amino acid identity) from the Artemisia genus (e.g., A. afra and A. absinthium) converted amorpha-4,11-diene to artemisinic alcohol (Komori et al. 2013). However, ADS homologs from other Artemisia species (e.g., A. absinthium, A. kurramensis, and A. maritima) did not produce amorpha-4,11-diene (Muangphrom et al. 2016); a homologous synthase from $A$. maritima produced amorphen4,11-ol (Muangphrom et al. 2018). Although further investigation is required, accumulated data is in favor of the hypothesis that artemisinin production in A. annua is attributed to the emergence of $A D S$.

\section{METABOLIC ENGINEERING OF ADS}

Microbial production of artemisinin is a milestone in the development of synthetic biology (Kung et al. 2018), which initiated from the expression of $A D S$ in engineered E. coli (Martin et al. 2003). To increase amorpha4,11-diene production, several improvements have been made (Table 1), including the development of a twophase partitioning bioreactor (Newman et al. 2006); identifying and enhancing the production of rate-limiting enzymes (Fig. 1), such as $M K, P M K, H M G S, H M G R$, and ADS (Anthony et al. 2009; Ma et al. 2011; ReddingJohanson et al. 2011; Tsuruta et al. 2009); increasing the flux of 1-deoxy-D-xylulose-5-phosphate by engineering the phosphoenolpyruvate-dependent phosphotransferase system (PTS; Zhang et al. 2013, 2015); systematically optimizing transcription and translation in E. coli (Shukal et al. 2019); and constructing multienzyme complexes in E. coli (Wei et al. 2020). Among these improvements, assembling and modulating efflux pumps in E. coli are vital because the accumulation of antimicrobial amorpha-4,11-diene in E. coli inhibited cell growth (Zhang et al. 2016; Wang et al. 2013). Collectively, the highest production of amorpha-4,11-diene was $27.4 \mathrm{~g} / \mathrm{L}$ (Tsuruta et al. 2009).

Although the production of amorpha-4,11-diene in engineered E. coli was successful, several enzymes are necessary to complete the transformation of amorpha4,11-diene to artemisinin, in which the cytochrome P450 CYP71AV1 catalyzes the first oxidation reaction (Teoh et al. 2006). N-terminal modified CYP71AV1 was heterologously expressed in E. coli (Chang et al. 2007); however, the functional expression of plant P450 in $E$. coli is extremely challenging because intracellular membrane structures are absent.

Yeast is considered a reliable host for the expression of plant P450. To facilitate the expression of CYP71AV1, two groups independently engineered yeast to produce 


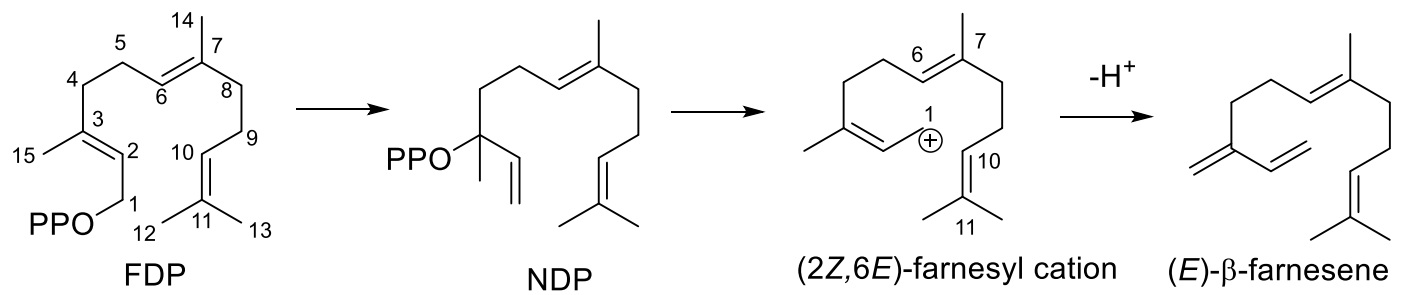

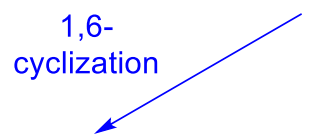<smiles>CC(C)=CCC[C@@H](C)[C@H]1CC=C(C)CC1</smiles>

$\alpha$-bisabolol

bisabolyl cation<smiles>CC(C)=CCCC(C)C1C=C[C@](C)(O)CC1</smiles>

zingeberenol

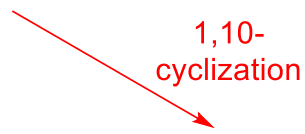<smiles>C=C1C=CC(C(C)CC(C=C(C)C)C(C)C)CC1</smiles>

$\beta$-sesquiphellandrene

$$
15
$$<smiles>C=C(C)[C@@H]1[C@H]2C=C(C)CC[C@@H]2[C@H](C)C[C@H]1C</smiles>

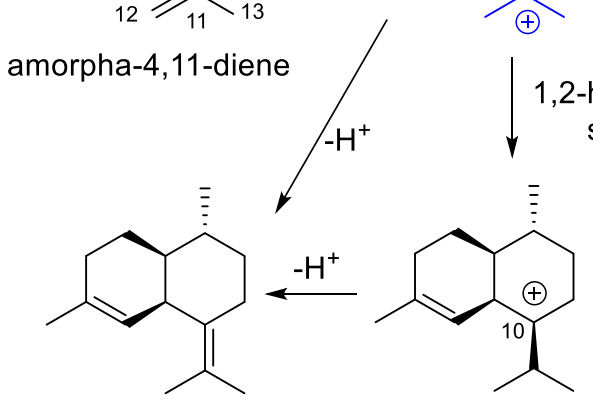

amorpha-4,7(11)-diene<smiles>C/C1=C/C[C@H](C(C)C)CC/C(C)=C/CC1</smiles>

(2Z,6E)-germacradienyl cation

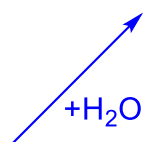<smiles>C[C+]CC1=CCC(C(C)CCC=C(C)C)C=C1</smiles>

zingeberene

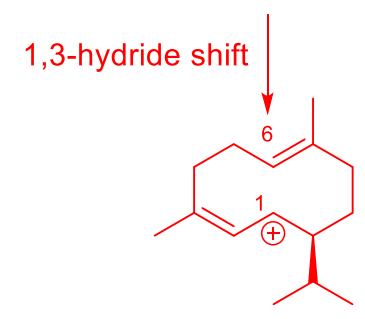

1,6cyclization

1,5-hydride shift<smiles>CC1=C[C@H]2[C@@H](CC1)CC[C@@H]2C(C)C</smiles>
$-\mathrm{H}^{+}$<smiles>CC1=C[C@@H]2[C@H](CC1)[C@H](C)CC[C@]2(O)C(C)C</smiles>

amorpha-4-en-7-ol<smiles>C=C1CCC2C(C1)C(C(C)C)CC[C@H]2I</smiles>

$\beta$-copaene

Fig. 2 Proposed cyclization mechanisms for the formation of amorpha-4,11-diene by ADS. Reactions starting from the initial 1,6-ring closure of FDP and the generation of bisabolene-type by-products are highlighted in blue. Steps proceeding through the initial 1,10-ring closure and corresponding by-products are marked in red

amorpha-4,11-diene in 2006. Lindahl et al. (2006) expressed $A D S$ in yeast using plasmids and chromosomal integration resulting in $0.6 \mathrm{mg} / \mathrm{L}$ and $0.1 \mathrm{mg} / \mathrm{L}$ amorpha-4,11-diene production, respectively, whereas
Ro et al. (2006) obtained $153 \mathrm{mg} / \mathrm{L}$ of amorpha-4,11diene by introducing $A D S$ into yeast that was simultaneously engineered by the overexpression of truncated HMGR, FPPS (ERG20), and an activated allele of the 


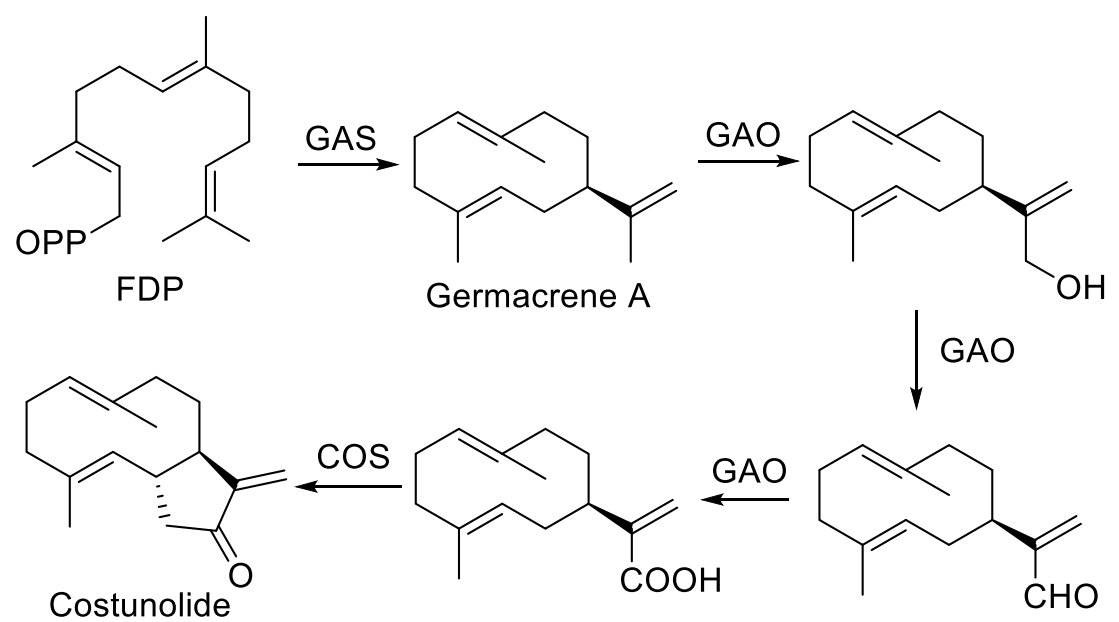

Fig. 3 Asteraceae sesquiterpene lactone biosynthetic pathway. GAS, germacrene A synthase; COS, costunolide synthase

UPC2 transcription factor (upc2-1) as well as the downregulation of the expression of squalene synthase (ERG9). Since then, other metabolic engineering methods have been used in yeast to increase amorpha-4,11diene production (Table 1). These methods include mutating the $A D S$ gene to the yeast-conform variant (Kong et al. 2009), using a high-copy plasmid system to express $A D S$ in yeast (Ro et al. 2008), downregulating the expression of ERG9 and fusing ADS with FPPS (Baadhe et al. 2013; Yuan and Ching 2015a), integrating the combinatorial genome of mevalonate (MVA) pathway genes in yeast (Yuan and Ching 2014), using knockout genes outside the isoprenoid pathway but improving isoprenoid fluxes (Sun et al. 2014), assembling MVA pathway genes into yeast chromosomes and reducing ERG9 expression (Yuan and Ching 2015b), and expressing MVA pathway genes and $A D S$ into yeast mitochondria (Farhi et al. 2011b; Yuan and Ching 2016). By overexpressing every enzyme of the MVA pathway, the production of amorpha-4,11-diene reached $41 \mathrm{~g} / \mathrm{L}$ (Westfall et al. 2012).

By expressing artemisinin pathway genes in microbial hosts, current biosynthetic methods only produced artemisinic acid. However, introducing artemisinin pathway genes in Nicotiana spp. resulted in the heterologous production of artemisinin, suggesting a metabolic engineering application of these plants in the production of artemisinin (Kram and Simonsen 2017). Initially, ADS was expressed in N. tabacum to characterize its function, but it only yielded $1.7 \mathrm{ng} / \mathrm{g}$ (fresh weight) of amorpha-4,11-diene (Wallaart et al. 2001). Methods similar to those for the microbial production of amorpha-4,11-diene (Table 1), such as coexpressing MVA pathway genes and targeting $A D S$ into mitochondria, chloroplasts, or plastids, were used to improve the accumulation of amorpha-4,11-diene (Farhi et al. 2011a;
Fuentes et al. 2016; Malhotra et al. 2016; van Herpen et al. 2010; Wu et al. 2006; Zhang et al. 2011). Using the moss Physcomitrella patens as a heterologous host avoided the glycosylation of pathway intermediates (Ikram et al. 2017, 2019), and this effect was similar to the expression of artemisinin pathway genes in the chloroplasts, nuclei, and mitochondria of $N$. tabacum (Fuentes et al. 2016; Malhotra et al. 2016).

The success of microbial production of amorpha4,11-diene in E. coli and yeast has promoted engineering other organisms for amorpha-4,11-diene production as proof-of-concept studies. For example, Bacillus subtilis was chosen because of its rapid growth rate and safe status (Pramastya et al. 2020; Song et al. 2021; Zhou et al. 2013), and cyanobacteria were engineered as biosolar cell factories for the photosynthetic conversion of $\mathrm{CO}_{2}$ to amorpha-4,11-diene (Choi et al. 2016). The industrial microorganism Streptomyces avermitilis was genetically engineered to produce amorpha-4,11-diene but none of its major endogenous secondary metabolites (Komatsu et al. 2010). Rhodobacter sphaeroides was used to test the growth-independent production of isoprenoids such as amorpha-4,11-diene (Orsi et al. 2020). Another strategy to produce high-value natural products is in vitro metabolic engineering, which has been applied for the production of amorpha-4,11-diene and some inhibitors of ADS such as ATP and pyrophosphate were identified (Chen et al. 2013; 2016).

\section{PROTEIN ENGINEERING AND CHEMOENZYMATIC APPLICATION OF ADS}

The above approaches in improving amorpha-4,11-diene production often involve the enhancement of the efficiency and production of rate-limiting enzymes in 
Table 1 Biosynthetic and metabolic engineering approaches to produce amorpha-4,11-diene

\begin{tabular}{|c|c|c|c|}
\hline Construction & Organism & Amorphadiene & References \\
\hline $\begin{array}{l}\text { Engineering codon-optimized ADS and mevalonate pathway } \\
\text { from } S \text {. cerevisiae in E. coli }\end{array}$ & E. coli & $24 \mathrm{mg} / \mathrm{L}$ & Martin et al. (2003) \\
\hline Enhancing production of rate-limiting enzymes MK and ADS & E. coli & $300 \mathrm{mg} / \mathrm{L}$ & Anthony et al. (2009) \\
\hline $\begin{array}{l}\text { Introducing more active HMG-CoA synthase and HMG-CoA } \\
\text { reductase }\end{array}$ & E. coli & $27.4 \mathrm{~g} / \mathrm{L}$ & Tsuruta et al. (2009) \\
\hline Enhancing production of rate-limiting enzymes MK and PMK & E. coli & $500 \mathrm{mg} / \mathrm{L}$ & $\begin{array}{l}\text { Redding-Johanson } \\
\text { et al. (2011) }\end{array}$ \\
\hline Introducing more active HMG-CoA reductase & E. coli & $700 \mathrm{mg} / \mathrm{L}$ & Ma et al. (2011) \\
\hline Engineering efflux pumps & E. coli & $363 \mathrm{mg} / \mathrm{L}$ & Wang et al. (2013) \\
\hline Deleting PTS & E. coli & $182 \mathrm{mg} / \mathrm{L}$ & Zhang et al. (2013) \\
\hline Engineering PTS and GGS & E. coli & $201 \mathrm{mg} / \mathrm{L}$ & Zhang et al. (2015) \\
\hline Efflux transporter engineering & E. coli & $150 \mathrm{mg} / \mathrm{L}$ & Zhang et al. (2016) \\
\hline $\begin{array}{l}\text { Systematically optimizing transcription and translation in } \\
\text { E. coli }\end{array}$ & E. coli & $30 \mathrm{~g} / \mathrm{L}$ & Shukal et al. (2019) \\
\hline Plasmid integration of $A D S$ into yeast & S. cerevisiae & $0.6 \mathrm{mg} / \mathrm{L}$ & Lindahl et al. (2006) \\
\hline Inserting $A D S$ into yeast genome & S. cerevisiae & $0.1 \mathrm{mg} / \mathrm{L}$ & Lindahl et al. (2006) \\
\hline $\begin{array}{l}\text { Overexpressing } t H M G R, E R G 20 \text {, and } u p c 2-1 \text {, and } \\
\text { downregulating } E R G 9\end{array}$ & S. cerevisiae & $153 \mathrm{mg} / \mathrm{L}$ & Ro et al. (2006) \\
\hline Increasing copy number of $A D S$ in yeast & S. cerevisiae & $781 \mathrm{mg} / \mathrm{L}$ & Ro et al. (2008) \\
\hline Engineering codon-optimized $A D S$ in $S$. cerevisiae & S. cerevisiae & $123 \mathrm{mg} / \mathrm{L}$ & Kong et al. (2009) \\
\hline Integrating $H M G 1, F D P S$, and $A D S$ into yeast mitochondria & S. cerevisiae & $20 \mathrm{mg} / \mathrm{L}$ & Farhi et al. (2011a) \\
\hline Overexpressing every enzyme of MVA pathway & S. cerevisiae & $41 \mathrm{~g} / \mathrm{L}$ & Westfall et al. (2012) \\
\hline Downregulating ERG9 and fusing $A D S$ with FPPS & S. cerevisiae & $25 \mathrm{mg} / \mathrm{L}$ & Baadhe et al. (2013) \\
\hline $\begin{array}{l}\text { Combinatorial genome integration of MVA pathway genes in } \\
\text { yeast }\end{array}$ & S. cerevisiae & $64 \mathrm{mg} / \mathrm{L}$ & Yuan and Ching (2014) \\
\hline $\begin{array}{l}\text { Knockout genes outside isoprenoid pathway but improving } \\
\text { isoprenoid fluxes }\end{array}$ & S. cerevisiae & $54.5 \mathrm{mg} / \mathrm{L}$ & Sun et al. (2014) \\
\hline Dynamic control of the expression of ERG9 & S. cerevisiae & $350 \mathrm{mg} / \mathrm{L}$ & Yuan and Ching (2015a) \\
\hline $\begin{array}{l}\text { Assembling MVA pathway genes into yeast chromosomes and } \\
\text { reducing ERG9 expression }\end{array}$ & S. cerevisiae & $500 \mathrm{mg} / \mathrm{L}$ & Yuan and Ching (2015b) \\
\hline $\begin{array}{l}\text { Integrating MVA pathway genes and } A D S \text { into yeast } \\
\text { mitochondria }\end{array}$ & S. cerevisiae & $427 \mathrm{mg} / \mathrm{L}$ & Yuan and Ching (2016) \\
\hline Expressing ADS in N. tabacum & N. tabacum & $1.7 \mathrm{ng} / \mathrm{g} \mathrm{FW}$ & Wallaart et al. (2001) \\
\hline Targeting FPS and ADS in plastids & N. tabacum & $25 \mu \mathrm{g} / \mathrm{g} \mathrm{FW}$ & Wu et al. (2006) \\
\hline Introducing $t H M G R, F P S$, and $A D S$ into $N$. benthamiana & N. benthamiana & $6.2 \mu \mathrm{g} / \mathrm{g} \mathrm{FW}$ & Van Herpen et al. (2010) \\
\hline Targeting FPS and ADS in plastids & N. tabacum & $4 \mu \mathrm{g} / \mathrm{g} \mathrm{FW}$ & Zhang et al. (2011) \\
\hline $\begin{array}{l}\text { Introducing } t H M G R \text { from yeast and } A D S, C P R, C Y P 71 A V 1 \text {, and } \\
D B R 2 \text { into } N \text {. tabacum }\end{array}$ & N. tabacum & 827 ng/g FW & Farhi et al. (2011b) \\
\hline $\begin{array}{l}\text { Introducing whole artemisinin pathway genes into } N \text {. tabacum } \\
\text { chloroplasts }\end{array}$ & N. tabacum & & Fuentes et al. (2016) \\
\hline $\begin{array}{l}\text { Engineering MVA and artemisinin pathway genes in N. tabacum } \\
\text { chloroplasts, nuclei, and mitochondria }\end{array}$ & N. tabacum & $60 \mu \mathrm{g} / \mathrm{g}$ DW & Malhotra et al. (2016) \\
\hline Engineering $A D S$ in $P$. patens & Physcomitrella patens & $200 \mathrm{mg} / \mathrm{L}$ & Ikram et al. (2017) \\
\hline Engineering $d x s$, idi, and $A D S$ in $B$. subtilis & B. subtilis & $20 \mathrm{mg} / \mathrm{L}$ & Zhou et al. (2013) \\
\hline $\begin{array}{l}\text { Chromosomally integrated GFP-ADS, FPPS, and a plasmid- } \\
\text { encoded synthetic operon carrying MEP pathway genes }\end{array}$ & B. subtilis & $416 \mathrm{mg} / \mathrm{L}$ & Pramastya et al. (2020) \\
\hline Engineering MEP pathway genes and $A D S$ in cyanobacteria & $\begin{array}{l}\text { Synechococcus elongatus } \\
\quad \text { PCC } 7942\end{array}$ & $19.8 \mathrm{mg} / \mathrm{L}$ & Choi et al. (2016) \\
\hline Engineering codon-optimized $A D S$ in $S$. avermitilis & S. avermitilis & $30 \mu \mathrm{g} / \mathrm{L}$ & Komatsu et al. (2010) \\
\hline Engineering $A D S$ in $R$. sphaeroides & R. sphaeroides & $56.4 \mathrm{mg} / \mathrm{L}$ & Orsi et al. (2020) \\
\hline
\end{tabular}


metabolic flux. However, protein engineering of ADS itself for higher catalytic efficiency has not been attempted. Engineering ADS is important because it catalyzes the first committed step in the formation of the artemisinin carbon skeleton but has poor catalytic activity. The classic metabolic engineering approach of increasing enzyme concentration to increase the production of target molecules is often limited by inherent low enzyme activity, particularly for TPS, which has 30 times lower enzyme activity than the central metabolism enzymes, which is also the case for ADS (Bar-Even et al. 2011). Protein engineering to improve the catalytic efficiency of TPS is a promising solution to this problem, which includes rational and non-rational engineering (Leonard et al. 2010). Non-rational engineering is based on error-prone PCR that introduces random mutations to a target gene, followed by the screening of clones for the desired function. Because of the lack of a highthroughput assay for screening mutant libraries, this method for engineering TPS is difficult (Lauchli et al. 2013). Thus, rational engineering of TPS is an alternative approach, which requires both knowledge of catalytic processes and understanding of the threedimensional structure of TPS.

In 2013, A. annua $\alpha$-bisabolol synthase (BOS) was isolated and functionally characterized to understand its crystal structure (Li et al. 2013). It shares $82 \%$ amino acid sequence identity and the bisabolyl cation as a common intermediate with ADS, providing a basis to find the active residues involved in ADS catalysis. After partially elucidating ADS catalysis, a T399S ADS variant that showed twofold higher turnover rate $\left(k_{\text {cat }}\right)$ because of accelerated product release was found ( $\mathrm{Li}$ et al. 2013). This inspired continuous investigation for rational engineering of ADS. As mentioned earlier, the ADS catalytic mechanism involves sequential 1,6 and 1,10 cyclization (Fig. 2). By using BOS (single 1,6 cyclization) and germacrene A synthase (single 1,10 cyclization) from $A$. annua as reference (Bertea et al. 2006), A. апnua phylogeny-based site-directed substitutions were performed. This led to the identification of seven residues in ADS controlling the whole cyclization process of amorpha-4,11-diene formation and a double mutation T399S/T447S that tripled $k_{\text {cat }}$ (Fang et al. 2017). Interestingly, the ADS T296V variant abolished the cyclization to the bisabolyl cation (Fang et al. 2017; Li et al. 2016; Abdallah et al. 2018). Four residues L374, L404, L405, and L439 were collectively responsible for the 1,10 cyclization, and T399 and T447 catalyzed the regioselective deprotonation and product release of ADS (Fang et al. 2017). To further identify active site residues, homology models of ADS based on a BOS variant (Abdallah et al. 2016) and TEAS (Eslami et al. 2017) were constructed. The root-mean-square deviation values between the BOS and TEAS models were $2.35 \AA$ and $0.302 \AA$ A respectively. Guided by the BOS model, extensive mutations were performed, leading to the identification of several residues influencing ADS catalysis. These residues included R262 for binding the PPi group; W271, Y519, and F525 for stabilizing intermediate carbocations; G400, G439, and L515 for the 1,10ring closure; T399 for regioselective deprotonation; and W271 as an active site catalytic base. A double mutation T399S/H448A that improved $k_{\text {cat }}$ by 5 times was also reported (Abdallah et al. 2016, 2018). Similarly, by using the TEAS model, residues identified were involved in FDP binding and determining the fate of the allylic carbocation intermediate. These residues included Y519, D444, W271, N443, T399, R262, V292, G400, and L405, which largely overlapped with those reported by other groups (Eslami et al. 2017). Collectively, these studies have provided insight into the sequence-function relationships of ADS and have impacted the industrial production of artemisinin by microbial fermentation.

In addition to catalytic efficiency, product specificity of ADS is another target of protein engineering. Heterologous expression of ADS in E. coli yielded 89\% of amorpha-4,11-diene (Newman et al. 2006), whereas an in vitro enzymatic reaction led to $80 \%$ of amorpha4,11-diene in addition to 15 by-products (Picaud et al. 2005), and one of these by-products, amorpha-4-en-11ol, was recently found to exist as an epimer of $6(R / S)$ amorpha-4-en-11-ol (Huang et al. 2021). In contrast, the recombinant ADS expressed in $N$. benthamiana produced $97 \%$ of amorpha-4,11-diene and 3\% of amorpha4,7(11)-diene in vitro (Kanagarajan et al. 2012), suggesting that CYP71AV1 may not be exposed to the above 14 by-products produced by ADS expressed in E. coli (except for amorpha-4,7(11)-diene) in planta. Recently, it was demonstrated that CYP71AV1 could not use any of the 15 by-products as substrates, including amorpha4,7(11)-diene and amorpha-4-en-7-ol, which are structurally similar to amorpha-4,11-diene, suggesting an overlooked issue to improve the fidelity of heterologously expressed ADS for more effective production of this artemisinin precursor by fermentation in E. coli (Huang et al. 2021).

By exploiting the substrate promiscuity of ADS, a chemoenzymatic strategy was recently developed for artemisinin production. Demiray et al. (2017) found that ADS accepted chemically synthesized 12-hydroxy-FDP as the substrate and converted it to dihydroartemisinic aldehyde. When the enzymatic reaction was performed using high-performance counter current chromatography, the yield of dihydroartemisinic aldehyde increased 


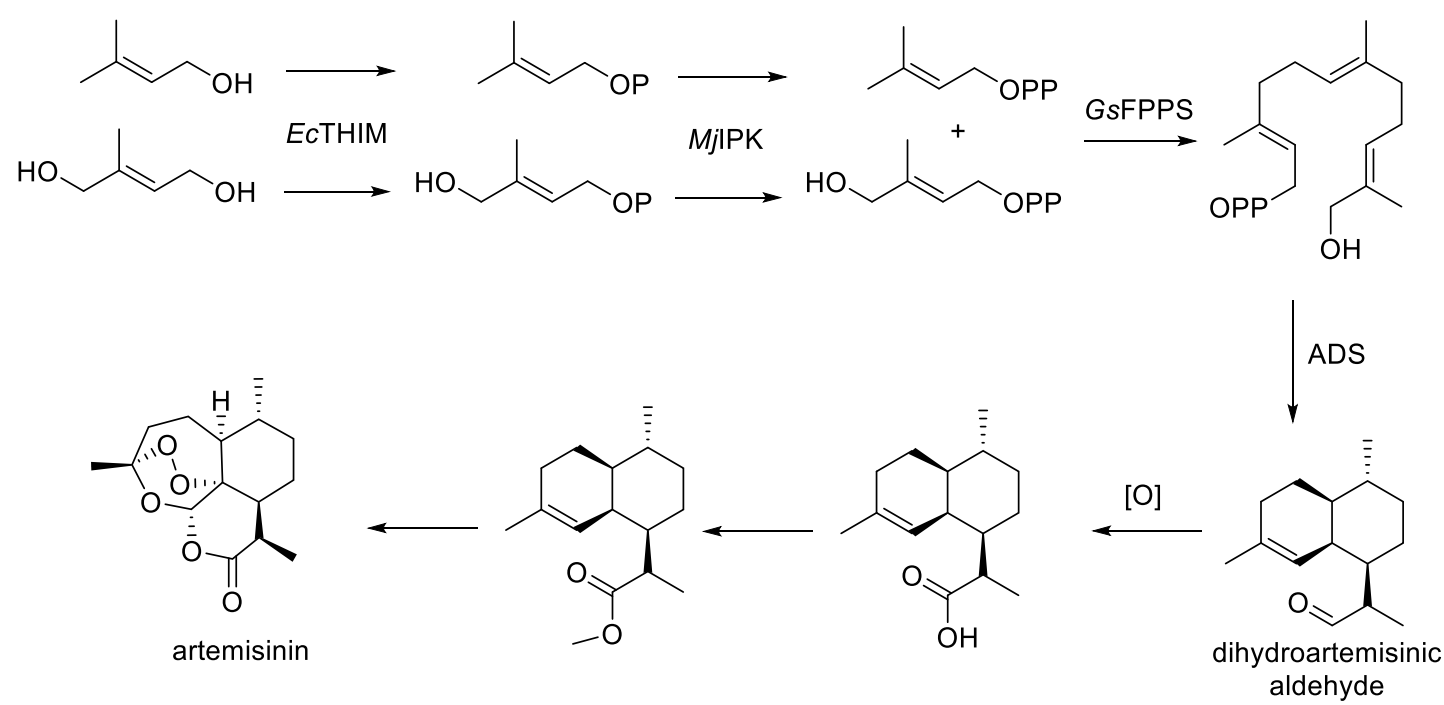

Fig. 4 Chemoenzymatic approach to synthesize artemisinin. EcTHIM, E. coli hydroxyethylthiazole kinase; MjIPK, Methanocaldococcus jannaschii isopentenyl phosphate kinase; GsFPPS, Geobacillus stearothermophilus farnesyl pyrophosphate synthase

from 20 to $60 \%$ and the reaction time reduced about tenfold (Huynh et al. 2020). In a few chemical steps, a high yield of artemisinin was obtained from this intermediate (Tang et al. 2018). Furthermore, by using the substrate promiscuity of kinases and FPPS, 12-hydroxyFDP was enzymatically synthesized in quantitative yield (Johnson et al. 2020). On reversing the oxidation order, the entire route was complementary to the biosynthetic approach (Fig. 4).

\section{CONCLUSION AND PERSPECTIVES}

ADS catalyzes the first committed step in the artemisinin biosynthetic pathway. Therefore, any approach using synthetic biology and metabolic engineering to synthesize artemisinin heterologously should start with the expression of ADS. Commercial scale production of semi-synthetic artemisinin was developed based on the progress of synthetic biology for artemisinin production. Evolutionarily, the emergence of ADS in A. annua essentially shapes a specialized artemisinin pathway from the costunolide pathway. Collectively, insights from these approaches have improved our knowledge and understanding of secondary metabolism biosynthesis, metabolic engineering, and synthetic biology.

However, some questions still remain unanswered. For example, bacterial systems used to express ADS produce $10 \%$ of by-products that cannot be used by downstream CYP71AV1. This reduces the efficiency of metabolic flux for artemisinin production by microbial fermentation and requires further investigation. Regarding the catalytic mechanism of ADS, the current mechanism was proposed based on mutation and labeled substrate experiments but was not supported by quantum chemical studies. Thus, X-ray crystallography data is needed. Besides, the three-dimensional structure of ADS expressed in E. coli and in planta will unravel the molecular basis for product promiscuity of recombinant ADS from E. coli.

More importantly, a question that needs to be answered is whether the conversion from artemisinic acid to artemisinin is dependent or independent of enzymes in planta. Although chemical transformation of these compounds is feasible in plant hosts-artemisinic acid is readily converted to artemisinin, such conversion is not feasible in microbial hosts. This observation suggests a missing enzymatic link between dihydroartemisinic acid and artemisinin in A. annua.

Acknowledgements This research was supported by the National Natural Science Foundation of China (31872666); the Special Fund for Talent Introduction of Kunming Institute of Botany, CAS; the China Postdoctoral Science Foundation (Grant Nos. 2020M671252 and 2020T130668); the Young Elite Scientists Sponsorship Program by CAST (2019QNRC001); the Open Fund of Shanghai Key Laboratory of Plant Functional Genomics and Resources (PFGR201902). We would also like to thank TopEdit (www.topeditsci.com) for English language editing of this manuscript.

\section{Declarations}

Conflicts of interest All the authors report no conflicts of interest. 
Open Access This article is licensed under a Creative Commons Attribution 4.0 International License, which permits use, sharing, adaptation, distribution and reproduction in any medium or format, as long as you give appropriate credit to the original author(s) and the source, provide a link to the Creative Commons licence, and indicate if changes were made. The images or other third party material in this article are included in the article's Creative Commons licence, unless indicated otherwise in a credit line to the material. If material is not included in the article's Creative Commons licence and your intended use is not permitted by statutory regulation or exceeds the permitted use, you will need to obtain permission directly from the copyright holder. To view a copy of this licence, visit http://creativecommons.org/ licenses/by/4.0/.

\section{References}

Abdallah II, Czepnik M, van Merkerk R, Quax WJ (2016) Insights into the three-dimensional structure of amorpha-4,11-diene synthase and probing of plasticity residues. J Nat Prod 79:2455-2463. https://doi.org/10.1021/acs.jnatprod. 6b00236

Abdallah II, van Merkerk R, Klumpenaar E, Quax WJ (2018) Catalysis of amorpha4,11-diene synthase unraveled and improved by mutability landscape guided engineering. Sci Rep 8:9961. https://doi.org/10.1038/s41598-018-28177-4

Alam P, Abdin MZ (2011) Over-expression of HMG-CoA reductase and amorpha-4,11-diene synthase genes in Artemisia annua L. and its influence on artemisinin content. Plant Cell Rep 30:1919-1928. https://doi.org/10.1007/s00299-011-10996

Anthony JR, Anthony LC, Nowroozi F, Kwon G, Newman JD, Keasling JD (2009) Optimization of the mevalonate-based isoprenoid biosynthetic pathway in Escherichia coli for production of the anti-malarial drug precursor amorpha4,11-diene. Metab Eng 11:13-19. https://doi.org/10.1016/j. ymben.2008.07.007

Baadhe RR, Mekala NK, Parcha SR, Devi YP (2013) Combination of ERG9 repression and enzyme fusion technology for improved production of amorphadiene in Saccharomyces cerevisiae. J Anal Methods Chem 2013:140469. https://doi.org/10. $1155 / 2013 / 140469$

Bar-Even A, Noor E, Savir Y, Liebermeister W, David D, Tawfi DS, Milo R (2011) The moderately efficient enzyme: evolutionary and physicochemical trends shaping enzyme parameters. Biochemistry 50:4402-4410. https://doi.org/10.1021/ bi2002289

Bertea CM, Voster A, Verstappen FWA, Massimo M, Beekwilder J, Bouwmeester HJ (2006) Isoprenoid biosynthesis in Artemisia annua: cloning and heterologous expression of a germacrene A synthase from a glandular trichome cDNA library. Arch Biochem Biophys 448:150-155. https://doi.org/10.1016/j. abb.2006.02.026

Boutanaev AM, Moses T, Zi J, Nelson DR, Mugford ST, Peters RJ, Osbourn A (2015) Investigation of terpene diversification across multiple sequenced plant genomes. Proc Natl Acad Sci USA 112:E81-E88. https://doi.org/10.1073/pnas. 1419547112

Bouwmeester HJ, Wallaart TE, Janssen MHA et al (1999) Amorpha-4,11-diene synthase catalyses the first probable step in artemisinin biosynthesis. Phytochemistry 52:843-854. https://doi.org/10.1016/S0031-9422(99)00206-X
Cai Y, Jia JW, Crock J, Lin ZX, Chen XY, Croteau R (2002) A cDNA clone for $\beta$-caryophyllene synthase from Artemisia annua. Phytochemistry 61:523-529. https://doi.org/10.1016/ S0031-9422(02)00265-0

Catania TM, Branigan CA, Stawniak N et al (2018) Silencing amorpha-4,11-diene synthase genes in Artemisia annua leads to FPP accumulation. Front Plant Sci 9:547. https://doi.org/ 10.3389/fpls.2018.00547

Chang YJ, Song SH, Park SH, Kim SU (2000) Amorpha-4,11-diene synthase of Artemisia annua: cDNA isolation and bacterial expression of a terpene synthase involved in artemisinin biosynthesis. Arch Biochem Biophys 383:178-184. https:// doi.org/10.1016/j.abb.2000.2061

Chang MCY, Eachus RA, Trieu W, Ro D-K, Keasling JD (2007) Engineering Escherichia coli for production of functionalized terpenoids using plant P450s. Nat Chem Biol 3:274-277. https://doi.org/10.1038/nchembio875

Chen X-Y, Xu Z (2016) Artemisinin and plant secondary metabolism. Sci Bull 61:1-2. https://doi.org/10.1007/ s11434-015-0987-5

Chen X, Zhang C, Zou R, Zhou K, Stephanopoulos G, Too HP (2013) Statistical experimental design guided optimization of a onepot biphasic multienzyme total synthesis of amorpha-4,11diene. PLoS ONE 8:e79650. https://doi.org/10.1371/journal. pone.0079650

Chen X, Zhang C, Zou R, Stephanopoulos G, Too H-P (2016) In vitro metabolic engineering of amorpha-4,11-diene biosynthesis at enhanced rate and specific yield of production. ACS Synth Biol 6:1691-1700. https://doi.org/10.1021/acssynbio. 6b00377

Choi SY, Lee HJ, Choi J et al (2016) Photosynthetic conversion of CO2 to farnesyl diphosphate-derived phytochemical (amorpha-4,11-diene and squalene) by engineered cyanobacteria. Biotechnol Biofuels 9:202. https://doi.org/10.1186/s13068016-0617-8

Christianson DW (2017) Structural and chemical biology of terpenoid cyclases. Chem Rev 117:11570-11648. https:// doi.org/10.1021/acs.chemrev.7b00287

Demiray M, Tang X, Wirth T, Faraldos JA, Allemann R (2017) An efficient chemoenzymatic synthesis of dihydroartemisinic aldehyde. Angew Chem Int Ed 56:4347-4350. https://doi. org/10.1002/anie.201609557

Eslami H, Mohtashami SK, Basmanj MT, Rahati M, Rahimi H (2017) An in-silico insight into the substrate binding characteristics of the active site of amorpha-4,11-diene synthase, a key enzyme in artemisinin biosynthesis. J Mol Model 23:202. https://doi.org/10.1007/s00894-017-3374-0

Fang X, Li JX, Huang JQ Xiao YL, Zhang P, Chen XY (2017) Systematic identification of functional residues of Artemisia annua amorpha-4,11-diene synthase. Biochem J 474:2191-2202. https://doi.org/10.1042/BCJ20170060

Farhi M, Marhevka E, Ben-Ari J et al (2011a) Generation of the potent anti-malarial drug artemisinin in tobacco. Nat Biotechnol 29:1072-1074. https://doi.org/10.1038/nbt1251

Farhi M, Marhevka E, Tania M et al (2011b) Harnessing yeast subcellular compartments for the production of plant terpenoids. Metab Eng 13:474-481. https://doi.org/10.1016/j. ymben.2011.05.001

Farhi M, Kozin M, Duchin S, Vainstein A (2013) Metabolic engineering of plants for artemisinin synthesis. Biotechnol Genet Eng 29:135-148. https://doi.org/10.1080/02648725. 2013.821283

Fuentes P, Zhou F, Erban A, Karcher D, Kopka J, Bock R (2016) A new synthetic biology approach allows transfer of an entire metabolic pathway from a medicinal plant to a biomass crop. eLife 5:e13664. https://doi.org/10.7554/eLife.13664 
Han J, Wang H, Kanagarajan S, Hao M, Lundgren A, Brodelius PE (2016) Promoting artemisinin biosynthesis in Artemisia annua plants by substrate channeling. Mol Plant 9:946-948. https://doi.org/10.1016/j.molp.2016.03.004

Hong YJ, Tantillo DJA (2010) tangled web-interconnecting pathways to amorphadiene and the amorphene sesquiterpenes. Chem Sci 1:609-614. https://doi.org/10.1039/c0sc00333f

Hua L, Matsuda SPT (1999) The molecular cloning of 8-epicedrol synthase from Artemisia annua. Arch Biochem Biophys 369:208-212. https://doi.org/10.1016/j.abb.1999.1357

Huang JQ Li DM, Tian X, Lin JL, Yang L, Xu JJ, Fang X (2021) Side products of recombinant amorpha-4,11-diene synthase and their effect on microbial artemisinin production. J Agric Food Chem 69:2168-2178. https://doi.org/10.1021/acs.jafc. 0c07462

Huynh F, Tailby M, Finniear A, Stephens K, Allemann RK, Wirth T (2020) Accelerating biphasic biocatalysis through new process windows. Angew Chem Int Ed 59:16490-16495. https://doi.org/10.1002/anie.202005183

Ikram NKBK, Simonsen HT (2017) A review of biotechnological artemisinin production in plants. Front Plant Sci 8:1966. https://doi.org/10.3389/fpls.2017.01966

Ikram NKBK, Kashkooli AB, Peramuna AV, van der Krol AR, Bouwmeester H, Simonsen HT (2017) Stable production of the antimalarial drug artemisinin in the moss Physcomitrella patens. Front Bioeng Biotechnol 5:47. https://doi.org/10. 3389/fbioe.2017.00047

Ikram NKBK, Kashkooli AB, Peramuna AV, van der Krol AR, Bouwmeester H, Simonsen HT (2019) Insights into heterologous biosynthesis of arteannuin $\mathrm{B}$ and artemisinin in Physcomitrella patens. Molecules 24:3822. https://doi.org/ $10.3390 /$ molecules 24213822

Jia JW, Crock J, Lu S, Croteau R, Chen XY (1999) (3R)-linalool synthase from Artemisia annua L.: cDNA isolation, characterization, and wound induction. Arch Biochem Biophys 372:143-149. https://doi.org/10.1016/j.abb.1999.1466

Johnson LA, Dunbabin A, Benton JCR, Mart RJ, Allemann RK (2020) Modular chemoenzymatic synthesis of terpenes and their analogues. Angew Chem Int Ed 59:8486-8490. https:// doi.org/10.1002/anie.202001744

Judd R, Bagley MC, Li M et al (2019) Artemisinin biosynthesis in non-glandular trichome cells of Artemisia annua. Mol Plant 12:704-714

Kanagarajan S, Muthusamy S, Gliszczyńska A, Lundgren A, Brodelius PE (2012) Functional expression and characterization of sesquiterpene synthases from Artemisia annua L. using transient expression system in Nicotiana benthamiana. Plant Cell Rep 31:1309-1319. https://doi.org/10.1007/ s00299-012-1250-Z

Kim SH, Heo K, Chang YJ, Park SH, Rhee SK, Kim SU (2006) Cyclization mechanism of amorpha-4,11-diene synthase, a key enzyme in artemisinin biosynthesis. J Nat Prod 69:758-762. https://doi.org/10.1021/np050356u

Komatsu M, Uchiyama T, Omura S, Cane DE, Ikeda H (2010) Genome-minimized Streptomyces host for the heterologous expression of secondary metabolism. Proc Natl Acad Sci USA 107:2646-2651. https://doi.org/10.1073/pnas.0914833107

Komori A, Suzuki M, Seki H et al (2013) Comparative functional analysis of CYP71AV1 natural variants reveals an important residue for the successive oxidation of amorpha-4,11-diene. FEBS Lett 587:278-284. https://doi.org/10.1016/j.febslet. 2012.11.031

Kong J-Q, Wang W, Wang L-N, Zheng X-D, Cheng K-D, Zhu P (2009) The improvement of amorpha-4,11-diene production by a yeast-conform variant. J Appl Microbiol 106:941-951. https://doi.org/10.1111/j.1365-2672.2008.04063.x
Kung SH, Lund S, Murarka A, McPhee D, Paddon CJ (2018) Approaches and recent developments for the commercial production of semi-synthetic artemisinin. Front Plant Sci 9:87. https://doi.org/10.3389/fpls.2018.00087

Lauchli R, Rabe KS, Kalbarczyk KZ, Tata A, Heel T, Kitto RZ, Arnold FH (2013) High-throughput screening for terpene-synthasecyclization activity and directed evolution of a terpene synthase. Angew Chem Int Ed 52:5571-5574. https://doi. org/10.1002/anie.201301362

Leonard E, Ajikumar PK, Thayer K et al (2010) Combining metabolic and protein engineering of a terpenoid biosynthetic pathway for overproduction and selectivity control. Proc Natl Acad Sci USA 113:13654-13659. https://doi.org/ 10.1073/pnas.1006138107

Li JX, Fang X, Zhao Q et al (2013) Rational engineering of plasticity residues of sesquiterpene synthases from Artemisia annua: product specificity and catalytic efficiency. Biochem J 451:417-426. https://doi.org/10.1042/BJ20130041

Li Z, Gao R, Hao Q et al (2016) The T296V mutant of amorpha4,11-diene synthase is defective in allylic diphosphate isomerization but retains the ability to cyclize the intermediate (3R)-nerolidyl diphosphate to amorpha-4,11-diene. Biochemistry 36:8332-8339. https://doi.org/10.1021/acs. biochem.6b01004

Lindahl A-L, Oslsson MK, Mercke P, Tollbom Ö, Schelin J, Brodelius M, Brodelius PE (2006) Production of the artemisinin precursor amorpha-4,11-diene by engineered Saccharomyces cerevisiae. Biotechnol Lett 28:571-580. https://doi.org/10. 1007/s10529-006-0015-6

Ma C, Wang H, Lu X, Wang H, Xu G, Liu B (2009) Terpenoid metabolic profiling analysis of transgenic Artemisia annua $\mathrm{L}$. by comprehensive two-dimensional gas chromatography time-of-flight mass spectrometry. Metabolomics 5:497-506. https://doi.org/10.1007/s11306-009-0170-6

Ma SM, Garcia DE, Redding-Johanson AM et al (2011) Optimization of a heterologous mevalonate pathway through the use of variant HMG-CoA reductases. Metab Eng 13:588-597. https://doi.org/10.1016/j.ymben.2011.07.001

Ma D-M, Wang Z, Wang L, Alejos-Gonzales F, Sun M-A, Xie D-Y (2015) A genome-wide scenario of terpene pathways in selfpollinated Artemisia annua. Mol Plant 8:1580-1598. https:// doi.org/10.1016/j.molp.2015.07.004

Malhotra K, Subramaniyan M, Rawat K et al (2016) Compartmentalized metabolic engineering for artemisinin biosynthesis and effective malaria treatment by oral delivery of plant cells. Mol Plant 9:1464-1477. https://doi.org/10.1016/j.molp. 2016.09.013

Martin VJJ, Pitera DJ, Withers ST, Newman JD, Keasling JD (2003) Engineering a mevalonate pathway in Escherichia coli for production of terpenoids. Nat Biotechnol 21:796-802. https://doi.org/10.1038/nbt833

Mercke P, Crock J, Croteau R, Brodelius PE (1999) Cloning, expression, and characterization of epi-cedrol synthase, a sesquiterpene cyclase from Artemisia annua L. Arch Biochem Biophys 369:213-222. https://doi.org/10.1016/j.abb.1999. 1358

Mercke P, Bengtsson M, Bouwmeester HJ, Posthumus MA, Brodelius PE (2000) Molecular cloning, expression, and characterization of amorpha-4,11-diene synthase, a key enzyme of artemisinin biosynthesis in Artemisia annua L. Arch Biochem Biophys 381:173-180. https://doi.org/10. 1016/j.abb.2000.1962

Muangphrom P, Seki H, Suzuki M et al (2016) Functional analysis of amorpha-4,11-diene synthase (ADS) homologs from nonartemisinin-producing Artemisia species: the discover of 
novel koidzumiol and $(+)-\alpha$-bisabolol synthases. Plant Cell Physiol 57:1678-1688

Muangphrom P, Seki H, Matsumoto S, Nishiwaki M, Fukushima EO, Muranaka T (2018) Identification and characterization of a novel sesquiterpene synthase, 4-amorphen-11-ol synthase, from Artemisia maritima. Plant Biotechnol Nar 35:113-121. https://doi.org/10.5511/plantbiotechnology.18.0324a

Newman JD, Marshall J, Chang $M$ et al (2006) High-level production of amorpha-4,11-diene in a two-phase partitioning bioreactor of metabolically engineered Escherichia coli. Biotechnol Bioeng 95:684-691. https://doi.org/10.1002/bit. 21017

Nguyen DT, Göpfert JC, Ikezawa N et al (2010) Biochemical conservation and evolution of germacrene A oxidase in Asteraceae. J Biol Chem 285:16588-16598. https://doi.org/ 10.1074/jbc.M110.111757

Nguyen T-D, Kwon M, Kim S-U, Fischer C, Ro D-K (2019) Catalytic plasticity of germacrene A oxidase underlies sesquiterpene lactone diversification. Plant Physiol 181:945-960. https:// doi.org/10.1104/pp.19.00629

Orsi E, Mougiakos I, Post W et al (2020) Growth-uncoupled isoprenoid synthesis in Rhodobacter sphaeroides. Biotechnol Biofuels 13:123. https://doi.org/10.1186/s13068-02001765-1

Paddon CJ, Keasling JD (2014) Semi-synthetic artemisinin: a model for the use of synthetic biology in pharmaceutical development. Nat Rev Microbiol 12:355-357. https://doi. org/10.1038/nrmicro3240

Paddon CJ, Westfall PJ, Pitera DJ et al (2013) High-level semisynthetic production of the potent antimalarial artemisinin. Nature 494:528-532. https://doi.org/10.1038/nature12051

Picaud S, Olofsson L, Brodelius M, Brodelius PE (2005) Expression, purification, and characterization of recombinant amorpha-4,11-diene synthase from Artemisia annua L. Arch Biochem Biophys 436:215-226. https://doi.org/10.1016/j. abb.2005.02.012

Picaud S, Mercke P, He X, Sterner O, Brodelius M, Cane DE, Brodelius PE (2006) Amorpha-4,11-diene synthase: mechanism and stereochemistry of the enzymatic cyclization of farnesyl diphosphate. Arch Biochem Biophys 448:150-155. https://doi.org/10.1016/j.abb.2005.07.015

Pramastya H, Xue D, Abdallah II, Setroikromo R, Quax WJ (2020) High level production of amorphadiene using Bacillus subtilis as an optimized terpenoid cell factory. New Biotechnol 60:159-167. https://doi.org/10.1016/j.nbt.2020.10.007

Redding-Johanson AM, Batth TS, Chan R (2011) Targeted proteomics for metabolic pathway optimization: application to terpene production. Mtab Eng 13:194-203. https://doi.org/ 10.1016/j.ymben.2010.12.005

Ro D-K, Paradise EM, Ouellet M et al (2006) Production of the antimalarial drug precursor artemisinic acid in engineered yeast. Nature 440:940-943. https://doi.org/10.1038/ nature 04640

Ro D-K, Ouellet M, Paradise EM et al (2008) Induction of multiple pleiotropic drug resistance genes in yeast engineered to produce an increased level of anti-malarial drug precursor, artemisinic acid. BMC Biotechnol 8:83. https://doi.org/10. 1186/1472-6750-8-83

Salmon M, Laurendon C, Vardakou M et al (2015) Emergence of terpene cyclization in Artemisia annua. Nat Commun 6:6143

Shukal S, Chen X, Zhang C (2019) Systematic engineering for highyield production of viridiflorol and amorphadiene in auxotrophic Escherichia coli. Mtab Eng 55:170-178. https://doi. org/10.1016/j.ymben.2019.07.007

Song Y, He S, Abdallah II et al (2021) Engineering of multiple modules to improve amorphadiene production in Bacillus subtilis using CRISPR-Cas9. J Agric Food Chem 69:4785-4794. https://doi.org/10.1021/acs.jafc.1c00498

Sun Z, Meng H, Li J, Wang J, Li Q, Wang Y, Zhang Y (2014) Identification of novel knockout targets for improving terpenoids biosynthesis in Saccharomyces cerevisiae. PLoS ONE 9:e112615. https://doi.org/10.1371/journal.pone. 0112615

Tang X, Demiray M, Wirth T, Allemann RK (2018) Concise synthesis of artemisinin from a farnesyl diphosphate analogue. Bioorgan Med Chem 26:1314-1319. https://doi.org/ 10.1016/j.bmc.2017.03.068

Teoh KH, Polichuk DR, Reed DW, Nowak G, Covello PS (2006) Artemisia annua L. (Asteraceae) trichome-specific cDNAs reveal CYP71AV1, a cytochrome P450 with a key role in the biosynthesis of the antimalarial sesquiterpene lactone artemisinin. FEBS Lett 580:1411-1416. https://doi.org/10. 1016/j.febslet.2006.01.065

Tsuruta H, Paddon CJ, Eng D et al (2009) High-level production of amorpha-4,11-diene, a precursor of the antimalarial agent artemisinin, in Escherichia coli. PLoS ONE 4:e4489. https:// doi.org/10.1371/journal.pone.0004489

Van Herpen TWJM, Cankar K, Nogueira M, Bosch D, Bouwmeester HJ, Beekwilder J (2010) Nicotiana benthamiana as a production platform for artemisinin precursors. PLOS ONE 5:e14222. https://doi.org/10.1371/journal.pone.0014222

Wallaart TE, Bouwmeester HJ, Hille J, Poppinga L, Maijers NCA (2001) Amorpha-4,11-diene synthase: cloning and functional expression of a key enzyme in the biosynthetic pathway of the novel antimalarial drug artemisinin. Planta 212:460-465. https://doi.org/10.1007/s004250000428

Wang J-F, Xiong Z-Q Li S-Y, Wang Y (2013) Enhancing isoprenoid production through systematically assembling and modulating efflux pumps in Escherichia coli. Appl Microbiol Biotechnol 97:8057-8067. https://doi.org/10.1007/s00253-0135062-z

Wang J, Xu C, Wong YK, Li Y, Liao F, Jiang T, Tu Y (2019) Artemisinin, the magic drug discovered from traditional Chinese medicine. Engineering 5:32-39. https://doi.org/10. 1016/j.eng.2018.11.011

Wei Q He S, Qu J, Xia J (2020) Synthetic multienzyme complexes assembled on virus-like particles for cascade biosynthesis in cellulo. Bioconjugate Chem 31:2413-2420. https://doi.org/ 10.1021/acs.bioconjchem.0c00476

Westfall PJ, Pitera DJ, Lenihan JR et al (2012) Production of amorphadiene in yeast, and its conversion to dihydroartemisinic acid, precursor to the antimalarial agent artemisinin. Proc Natl Acad Sci USA 109:E111-E118. https://doi.org/10.1073/pnas.1110740109

Wu S, Schalk M, Clark A, Miles RB, Coates R, Chappell J (2006) Redirection of cytosolic or plastidic isoprenoid precursors elevates terpene production in plants. Nat Biotechnol 24:1441-1447. https://doi.org/10.1038/nbt1251

Xie DY, Ma DM, Judd R, Jones AL (2016) Artemisinin biosynthesis in Artemisia annua and metabolic engineering: questions, challenges, and perspectives. Phytochem Rev 15:1093-1114. https://doi.org/10.1007/s11101-016-9480-2

Yuan J, Ching C-B (2014) Combinatorial engineering of mevalonate pathway for improved amorpha-4,11-diene production in budding yeast. Biotechnol Bioeng 111:608-617. https://doi. org/10.1002/bit.25123

Yuan J, Ching C-B (2015a) Dynamic control of ERG9 expression for improved amorpha-4,11-diene production in Saccharomyces cerevisiae. Microb Cell Fact 14:38. https://doi.org/10.1186/ s12934-015-0220-x

Yuan J, Ching C-B (2015) Combinatorial assembly of large biochemical pathways into yeast chromosomes for improved 
production of value-added compounds. ACS Synth Biol $14: 23-31$

Yuan J, Ching C-B (2016) Mitochondrial acetyl-CoA utilization pathway for terpenoid productions. Metab Eng 38:303-309. https://doi.org/10.1016/j.ymben.2016.07.008

Zhang Y, Nowak G, Reed DW, Covello PS (2011) The production of artemisinin precursors in tobacco. Plant Biotechnol J 9:445-454. https://doi.org/10.1111/j.1467-7652.2010. 00556.x

Zhang C, Chen X, Zou R, Stephanopoulos G, Too H-P (2013) Combining genotype improvement and statistical media optimization for isoprenoid production in E. coli. Plos ONE 8:75164. https://doi.org/10.1371/journal.pone.0075164

Zhang C, Zou R, Chen X, Stephanopoulos G, Too H-R (2015)

Experimental design-aided systematic pathway optimization of glucose uptake and deoxyxylulose phosphate pathway for improved amorphadiene production. Appl Microbiol Biotechnol 99:3825-3837. https://doi.org/10.1007/s00253-0156463-y

Zhang C, Chen X, Stephanopoulos G, Too H-P (2016) Efflux transporter engineering markedly improved amorphadiene production in Escherichia coli. Biotechnol Bioeng 113:1755-1763. https://doi.org/10.1002/bit.25943

Zhou K, Zou R, Zhang C, Stephanopoulos G, Too H-P (2013) Optimization of amorphadiene synthesis in Bacillus subtilis via transcriptional, translational, and media modulation. Biotechnol Bioeng 110:2556-2561. https://doi.org/10. 1002/bit.24900 